\title{
REPRODUCTIVE CONSEQUENCES OF INSECT SEED PREDATION IN HAMAMELIS VIRGINIANA ${ }^{1}$
}

\author{
DiAne De Steven ${ }^{2}$ \\ Division of Biological Sciences, University of Michigan, \\ Ann Arbor, Michigan 48109 USA
}

\begin{abstract}
Through the use of populations of marked individuals over a 4-yr period, I studied the demographic impact on a temperate forest shrub, witch-hazel (Hamamelis virginiana), of predispersal seed predation by a host-specific weevil ( $P$ seudanthonomus hamamelidis). The general consequences of seed predation for witch-hazel recruitment are dependent upon the interaction of seed predation with the pattern of annual fruit production. Fruit production was poor in 1977 and 1978, and in these $2 \mathrm{yr}$, seed predation intensities (percent fruits attacked per crop) averaged $80-90 \%$. In 1979, fruit crop sizes increased dramatically, resulting in only $45 \%$ seed predation on average. Fruit production declined again in 1980 , and the weevils were able to attack nearly $100 \%$ of the available fruit. Thus at the population level, successful seed production is episodic, with large numbers of seeds being produced in the occasional good fruiting year through satiation of seed predators. The host specificity of Pseudanthonomus provides a mechanism for direct limitation of weevil population size in poor fruiting years.

I also evaluated the effect of seed predation on the relative contributions of different witch-hazel individuals to successful seed production. The distribution of individual plant fecundity in any given year is highly skewed, with only a few plants in the population producing large fruit crops. In any given year, more fecund plants incur neither higher nor lower percent fruit attack on average than less fecund individuals. Seed predation therefore does not change the relative contributions of different-sized individuals to annual seed production; more fecund plants produce more viable seeds than do less fecund plants, and the few highly fecund individuals in the population make a disproportionately large contribution. Between-plant variation in witch-hazel fecundity is thus significant demographically, even though it may not be subject to natural selection from seed predation pressure in these populations. The spatial distribution of witch-hazel is highly clumped, with few individuals being very isolated from conspecifics. Spatial isolation reduced the probability of a plant's location by weevils only in the case of small, low-fecundity individuals; large individuals, in contrast, were likely to be found regardless of distance from other conspecifics. Among the larger plants there were slight but nonsignificant tendencies for percent fruit attack to be lower with increased distance from conspecifics. Spatial isolation in this system seems important in lowering seed predation intensity only in interaction with individual plant fecundity.
\end{abstract}

Key words: Curculionidae; Hamamelis virginiana; mast fruiting; Michigan; plant demography; predator satiation; Pseudanthonomus hamamelidis; seed predation; weevil; witch-hazel.

\section{INTRODUCTION}

Seed production is a critical stage in the life history of plants. Seeds contribute to adult replacement and to increases in local population size, and are also the means of dispersal to areas distant from the local population (cf. Harper 1977). Predation by animals is a potentially important influence on the seed stage, with consequences for plant abundance, distribution, and evolution (Harper et al. 1970, Janzen 1971, Brown et al. 1979). Considerable interest has focussed upon interspecific and community patterns of coevolution between seed predators and their host plants (e.g., Janzen 1969, Smith 1970, Dolinger et al. 1973, Bradford and Smith 1977). The short-term demographic aspects of seed predation have only recently been investigated in detail, yet knowledge of the effects of seed predation at the level of single populations is important to

\footnotetext{
${ }^{1}$ Manuscript received 6 June 1981; revised 16 March 1982 accepted 14 April 1982.

${ }^{2}$ Present address: Department of Botany, Duke University, Durham, North Carolina 27706 USA.
}

understanding the mechanisms that might generate the hypothesized coevolved patterns.

Seed predation may influence plants at both population and individual levels. At the population level, potential effects include: (1) lower recruitment rate due to reduction in occupancy of "safe sites" (Harper 1977) suitable for germination and establishment, (2) discontinuous recruitment due to periodic or "mast" fruiting and the accompanying satiation of seed predators (Janzen 1971), and (3) alteration of adult distribution, if seed predation is density dependent (Janzen 1970, but see Hubbell 1980). The potential consequences of seed predation at the individual level are more interesting but less widely explored. Particularly when seeds are immature and still retained on the parent, adult characters such as fecundity, timing of seed production, and spatial location may influence the severity of predispersal predation on different individuals (cf. Moore 1978a). The ecological result is that the relative contribution of some adults to successful seed production will be greater than that of others, and may be so consistently from year to year. The evolutionary 


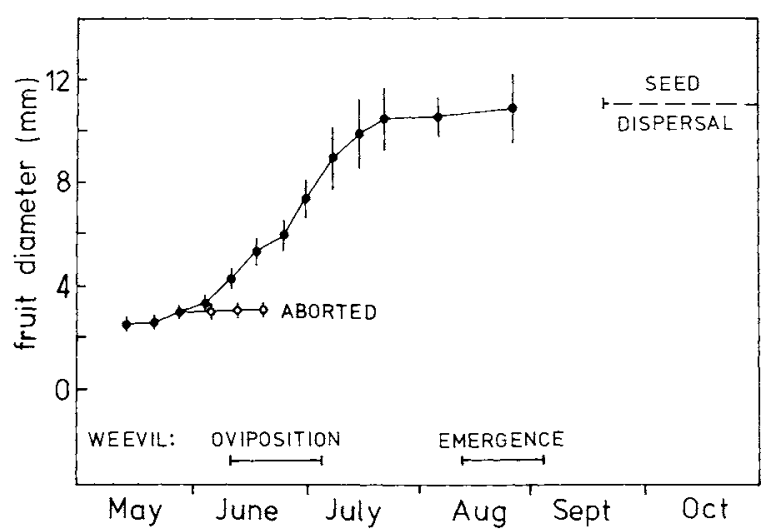

FIG. 1. Growth and development of witch-hazel fruits in relation to the seasonal phenology of Pseudanthonomus hamamelidis oviposition and new adult emergence. Estimates of mean fruit diameter at each time interval (closed circles) are based on samples of at least 30 fruit; vertical lines are one standard deviation on either side of the mean. "Aborted" fruits cease growth and are not used by weevils for oviposition.

result is a selective force upon adult characters that confer relative escape from predation, if these traits are heritable. Few studies have considered the extent and causes of individual variation in losses to seed predators (Moore 1978a, $b$, Silander 1978, Zimmerman 1980, De Steven $1981 b$ ), and generally not for more than a single year.

I studied predispersal seed predation by a host-specific insect (Pseudanthonomus hamamelidis Pierce, Coleoptera: Curculionidae) on witch-hazel (Hamamelis virginiana L., Hamamelidaceae), a common temperate forest shrub, with attention to the potential demographic consequences at both the population and individual levels. The severity of seed predation was quantified over $4 \mathrm{yr}$, including both high and low levels of fruit availability to the weevil. I first assess the overall impact of seed predation on the probable pattern of population recruitment, and the interaction of seed predation with patterns of witch-hazel fruit production. I then evaluate the relative contributions of different individuals within populations to successful seed production. The effects of fecundity and relative spatial isolation from conspecifics, two factors likely to influence differential seed predation in this species, are assessed through tests of the hypotheses that: (1) individual plant fecundity and seed predation intensity are inversely related, and (2) greater relative spatial isolation results in lower seed predation intensity (cf. Janzen 1970). Finally, I also consider aspects of the seed predator's population dynamics that have significant consequences for witch-hazel seed production.

\section{Natural History}

\section{Plant}

Witch-hazel is broadly distributed over eastern North America, coincident with the extent of eastern decid- uous forest (Preston 1948), and may be found in a number of site types (Wood 1974). Mature plants range from 3 to $5 \mathrm{~m}$ in height, with exceptional individuals reaching $8 \mathrm{~m}$ (Wood 1974). Plants can produce sucker sprouts from the base; however, this capacity is limited, and individual plants always remain distinct from each other. Most plants have 1 to 4 major stems, but larger individuals may have up to 10 .

The species is unusual in its autumn flowering habit (generally from September to November). Flowers appear to be insect pollinated but not specialized with respect to specific pollinator type. One early worker (Graenicher 1906) collected insect visitors from 44 genera distributed among the Diptera, Hymenoptera, Lepidoptera, and Coleoptera. However, the flowers are also self-compatible and self-pollinating (D. De Steven, personal observation). Despite the autumn flowering period, fertilization of ovules is delayed until the following May (Shoemaker 1905, Flint 1957), with the result that fruit development is coincident with that of other forest fruits and nuts. The two-seeded capsular fruits grow to full size by mid-August, but seed dispersal does not begin until late September, after a ripening period during which the capsule walls become woody and seeds mature (Fig. 1). Seed dispersal is accomplished by mechanical expulsion from the drying and dehiscing capsule; animals appear to play a minor role, if any, in seed dispersal (United States Forest Service 1974). After dispersal, seeds are dormant for two winters prior to germinating (Shoemaker 1905, Sandahl 1941).

Seedling growth rate is variable, depending upon moisture and light conditions in the understory (Wood 1974). The demography of juvenile and adult stages is virtually unknown. The shrub's suckering capacity permits vegetative persistence of individual plants for many years, which complicates demographic analysis because the oldest extant stem may be younger than the entire plant if older stems have died. The youngest flowering ramets in the witch-hazel populations that I studied had an estimated age (from stem annual ring counts) of $7 \mathrm{yr}$, but may have been older if they were suppressed during the initial seedling stage. The oldest stems examined were $\approx 30 \mathrm{yr}$ of age.

\section{Insect}

Pseudanthonomus hamamelidis belongs to a genus of small weevils whose larvae feed within fruits or flower buds (Burke 1972). Witch-hazel is the only recorded host plant (Blatchley and Leng 1916). P. hamamelidis overwinters in the adult stage. These adults emerge from hibernation in mid-May, when fruits are set, but oviposition does not begin until mid-June, when fruits are sufficiently large to support weevil larval growth (Fig. 1). The female weevil bores a hole into the fruit pericarp with her snout and deposits an egg within the pit. Usually eggs are laid singly on fruits (De Steven 1981a). The oviposition marks are quite conspicuous on the fruit surface; thus, it is easy to 
assess accurately whether or not a given fruit has been attacked by the weevil.

Most oviposition is completed by early July. The weevil larva burrows into the fruit upon hatching and eventually consumes both developing seeds. By midAugust feeding is complete, and larvae have pupated within the damaged fruits. The new adults emerge from mid-August to early September, prior to the onset of seed dispersal (Fig. 1). These adults hibernate, presumably in the forest litter, until the following spring.

\section{Methods \\ Field procedures}

The study was carried out from 1977 through 1980 at the E. S. George Reserve, Livingston County, Michigan, a 464-ha tract of oak-hickory forest, old fields, and marshland. A history of the Reserve and a detailed description are given in Cantrall (1943). Witchhazel is an abundant shrub within the forest and occurs there in more or less distinct stands. Four such stands were selected for study in widely separated areas of the forest. Two stands ( $\mathrm{L} 1$ and $\mathrm{L} 2$ ) were relatively large in extent $(>0.2 \mathrm{ha}$ ), while the other two ( $\mathrm{S} 1$ and S2) were small, each covering roughly a $20 \times 20 \mathrm{~m}$ area.

Within each large stand, a $20 \times 20 \mathrm{~m}$ plot was established for intensive study; the two small stands were used in entirety as comparable study plots, being of similar area. All fruiting witch-hazel plants had been individually tagged in 1977 , when only preliminary data were collected. In $1978, \approx 20$ individuals were selected randomly from the sample pool of marked plants in each plot to serve as the sample plants for each site. Any of the selected plants not bearing fruit was replaced by another drawn from the sample pool. In addition, to provide supplemental data on the effects of spatial isolation, three to five plants were added to the samples in each site specifically on the basis of their unusually large distances from other conspecifics. In the following year, 1979, the same individual plants were used initially. Any among these not bearing fruit were replaced either by plants that had been eliminated from the 1978 initial random sample for lack of fruit in that year, or (if these still bore no fruit in 1979) by new individuals from the original sample pool. The same plants were used again in 1980, with any necessary substitutions being made from the 1978 sample as before. Usually only one to two plants had to be replaced in this manner in a given site, so that overlap in individual composition of the sample plants was quite high between years. In general, the sample from each plot in each year contained 25-27 plants; however, the samples were smaller in the small plots (S1 and S2) in 1978 because relatively few plants fruited in those sites in that year. Including those individuals that fruited in one year and not another, a total of 105 individuals was monitored over the $4 \mathrm{yr}, 1977-$ 1980.
For each sample plant in each year, both the total number of fruits and the number of these with weevil oviposition marks were counted directly. The former provides an estimate of the number of fruits available to the weevils (which I refer to as plant fecundity in this paper), and the latter estimates predation intensity on individual fruit crops. These counts were made in the 1st wk in July, just after the weevil's peak oviposition period but before substantial abortion of fruits damaged by larval feeding (De Steven 1982). These counts are not equivalent to fruit-set, because some fruits are physiologically aborted before weevil oviposition begins (De Steven 1982; cf. Fig. 1), but I use these counts as measures of fecundity because they represent the fruit crop sizes that the plants would probably mature if no mortality from animals occurred. At the end of the growing season in early September, the total number of viable fruit remaining on each plant in each year was counted directly as well, to provide estimates of the number of seeds available for dispersal.

For each plant, distances (taken between the bases of stem clumps) to the three nearest witch-hazel plants also in fruit in a given year were measured and averaged to provide an index of relative spatial isolation.

\section{Analysis}

Frequency distributions of plant fecundity and percent fruit attack were markedly non-normal; in these cases, descriptive statistics are presented as medians bracketed by the 25 th and 75 th percentile. In other cases, data met the assumptions of parametric statistical tests when transformed logarithmically. Because many plants had extremely low fecundity ( $<10$ fruits) and thus a large variance in the estimates of predation intensity (percent fruit attack), tests involving percentage predation estimates were performed only on the subset of plants with fecundities of 10 or more fruit. Nonparametric tests were used when analyzing percentage data.

\section{RESUlTS}

\section{Witch-hazel fruit production}

Individual fecundity is highly variable within populations in any given year (Fig. 2). Most plants produce $<50$ fruits, and only a small number bear more than a few hundred fruits. The skewed distributions reflect in part the size structure of the reproductive population, as fruit-set and stem basal area (an index of plant size) were positively correlated (for 1978, $r=$ $.75, n=70, P<.01$ ), and fecundity (fruits available to weevils) is directly proportional to initial fruit-set (for 1978, $r=.93, n=82, P<.01$; correlations similar for other years; D. De Steven, personal observation).

Annual fruit production varied significantly over the period of the study (Kruskal-Wallis $H=20.3$, $\mathrm{df}=3$, $P<.001)$. Fruit crop sizes were similar in 1977 and 


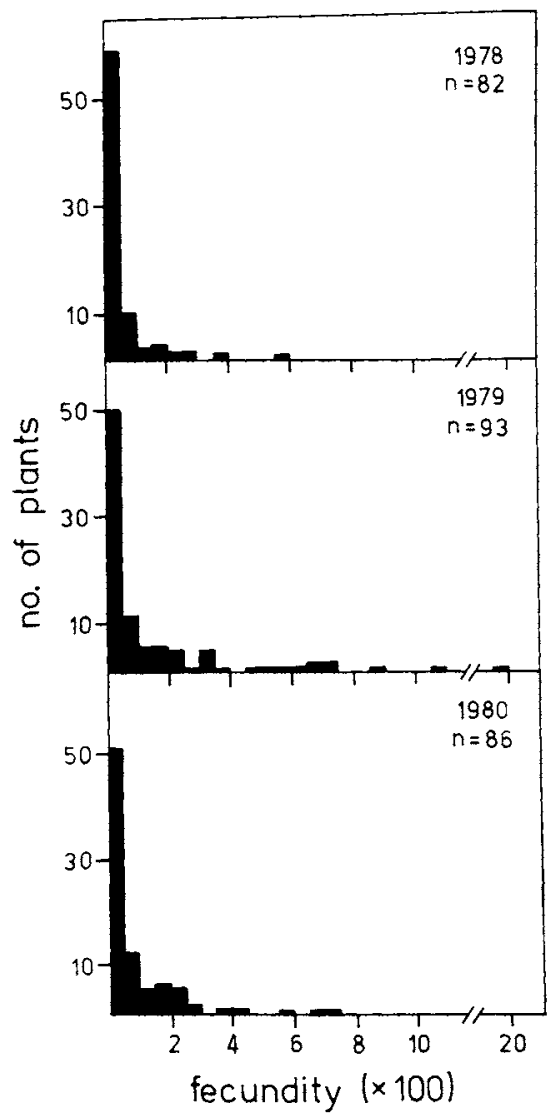

FIG. 2. Frequency distribution of individual witch-hazel plant fecundity from 1978 to 1980 . Fecundity values represent the number of fruits available to weevils for oviposition. Available fruits are those which escaped physiological abortion before weevil oviposition began.

1978 (Fig. 3A), although the 1977 data were incomplete and collected somewhat later in the summer than during the other years of the study. In contrast, the sample plants produced many more fruits in 1979 (Fig. 3A) (Mann-Whitney $U=2668.5, n_{1978}=82, n_{1979}=93$, $P<.001$ ). A matched-pairs test (Wilcoxon's signedranks test, sum of ranks $=2249.0, n=72, P<.001$ ) shows this general increase to be the result of the common behavior of most individuals in the population, i.e., most plants increased fruit crop size from 1978 to 1979. In 1980 , fruit production generally declined, although the difference was not significant $(U=3455.0$, $n_{1979}=93, n_{1980}=86, P=, 12$ ), and it was somewhat higher than the 1977-1978 levels (Fig. 3A). Again, most individuals participated in the general decrease in fruit production from 1979 to 1980 (Wilcoxon's signed-ranks test, sum of ranks $=2102.5, n=78, P<.001$ ). Thus a productive year was interspersed with three relatively poor fruiting years, and individuals were synchronized in this behavior.

Site-specific data for $3 \mathrm{yr}$ are included in Appendix 1. Each site exhibited the general trend of a fecundity

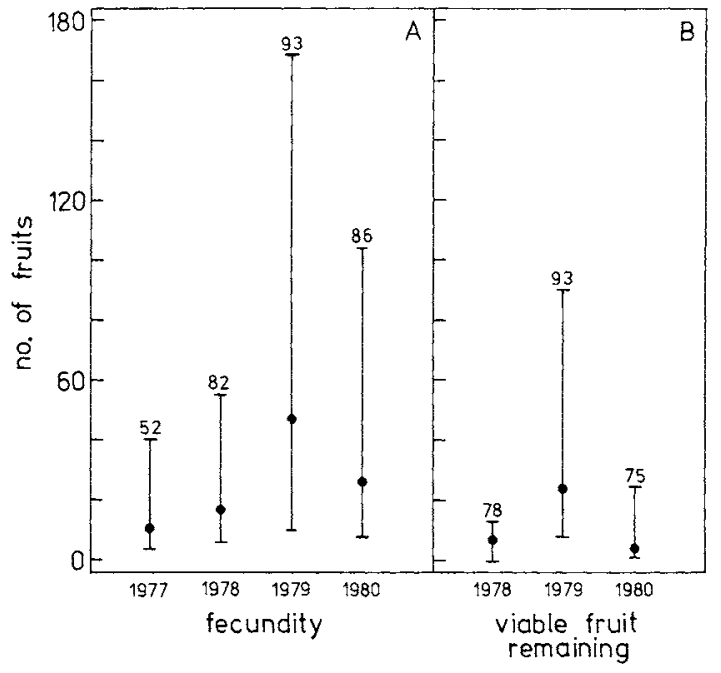

FIG. 3. A. Annual variation in witch-hazel fecundity from 1977 to 1980 . The circles are medians, and vertical lines bracket the interval from the 25 th to 75 th percentile. Numbers above each vertical line are numbers of plants in each annual sample. B. Viable fruits remaining on the plants at the end of the growing season from 1978 to 1980 . Interpretation as in $3 \mathrm{~A}$.

increase in 1979 and decline in 1980 except site S2, where median crop sizes remained similar over all 3 yr (Kruskal-Wallis $H=.14$, $\mathrm{df}=2, P \gg .10$ ). This site showed an interesting departure from the general pattern of seed predation observed, as indicated in the next section.

\section{Weevil seed predation: population patterns}

Predation intensity is measured as the percentage of an individual's fruit crop attacked by weevils. I distinguish between weevil attack (oviposition on fruits) and weevil damage (actual seed destruction) because, as explained later, weevil larvae may die within the fruits before completely destroying both seeds.

Predation intensities in the $4 \mathrm{yr}$ of the study are summarized in Fig. 4. When the study was initiated in 1977 , it appeared that nearly all fruits were infested by the weevils, and in 1978, when more complete data were collected, predation intensities were again high, generally $>80 \%$. In 1979, when fruits were much more abundant, weevil attack was significantly lower, averaging $45 \%\left(U=363.0, n_{1978}=50, n_{1979}=68, P<\right.$ .001 ). In 1980, when fruit crops had declined from 1979 levels, predation intensities were quite high.

On a site-by-site basis, where fecundity exhibited strong increases from 1978 to 1979 , seed predation intensities were reduced; however, in site S2, where fecundity had not increased, no real reduction occurred (for S2: $U=37.0, n_{1978}=8, n_{1979}=14, P>.10$; tests significant for all other sites; Appendix 2).

Fruits with both seeds damaged by weevil larval feeding are aborted and fall from the plant; larval de- 


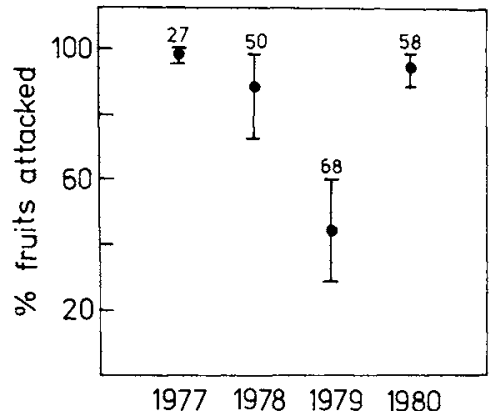

FIG. 4. Percent of individual witch-hazel fruit crops attacked by weevils from 1977 to 1980 . Only plants with fecundities of $\geqslant 10$ fruits are included (see text). Interpretation as in Fig. 3.

velopment can still proceed within them. By the end of the summer, only fruits containing viable seeds remain on the plants, and there are minor fruit losses to mammals up to the time of seed dispersal (De Steven 1982). Counts of remaining viable fruit for $3 \mathrm{yr}$, compared to initial fecundities, are summarized in Fig. 3B. The combination of higher fruit production and lower seed predation intensity resulted in substantially greater viable fruit production in 1979 than in either 1978 or $1980(H=38.7$, df $=2, P<.001)$. Counts of viable fruit were not made in 1977 but were probably comparable to 1978 , since these $2 \mathrm{yr}$ were similar in having low fruit production and high weevil attack. Thus the input of viable seeds into the soil is substantially higher in a year of good witch-hazel fruit production than during years of poor production, and this pattern is enhanced as a result of weevil seed predation. This episodic pattern of viable fruit production was similar in all sites except $\mathbf{S} 2$, where similar numbers of fruits were produced in both 1979 and 1980 (Appendix 3).

Often only one seed within a fruit is damaged by weevil feeding, the other seed remaining intact because the weevil larva dies before completely destroying the fruit (see below). The mean number of seeds per viable fruit was 1.4 in both 1978 and $1979(n=$ $853)$ and 1.0 in $1980(n=44)$.

\section{Weevil seed predation: variation among individuals}

Effect of fecundity.-Fecundity is highly variable and skewed in distribution, with only a few individuals producing large numbers of fruit (cf. Fig. 2). The relationship between individual fecundity and predation intensity is presented for each year in Fig. 5. Large variation in percent fruit attack is apparent in all years, especially among those individuals whose fecundities are very low ( $<10$ fruits) and variances correspondingly high due to the small sample size represented by a small fruit crop. While the percentage estimates for such small, low-fecundity plants are statistically un-

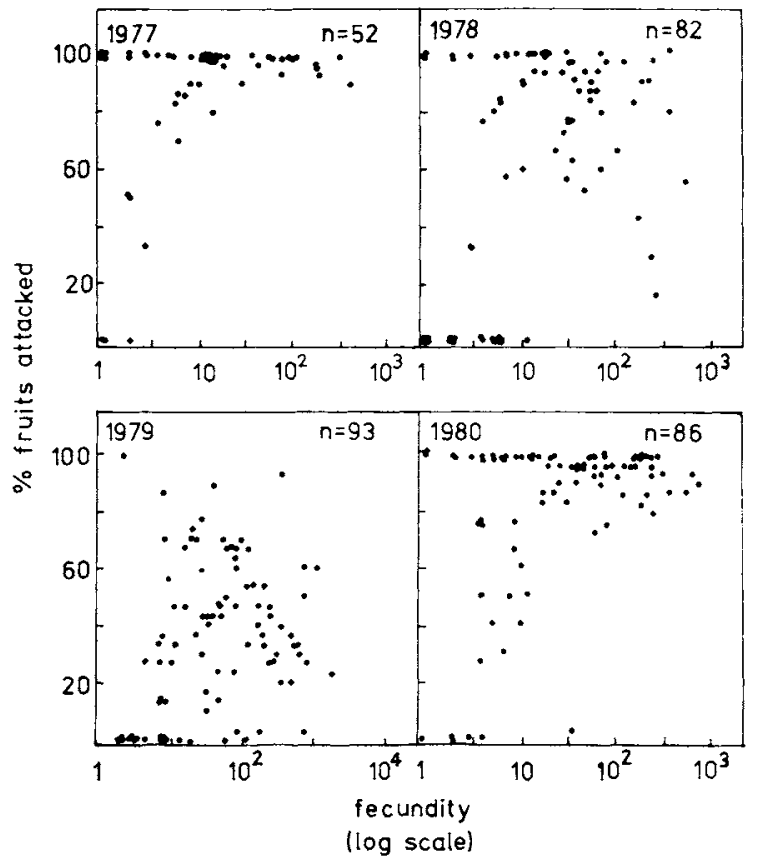

FIG. 5. Percent of individual witch-hazel fruit crops attacked by weevils as a function of plant fecundity from 1977 to 1980 .

reliable, their variability also probably reflects biological features of the predation process. If small plants are located by weevils, most or all of the fruits will be attacked, since female weevils may lay at least 3-6 eggs/d (D. De Steven, personal observation); however, such plants may be missed entirely and thus will sustain no damage. Larger plants, in contrast, are more likely to be found by weevils. The small, low-fecundity plants will be considered in more detail in the next section. For plants with fecundities $\geqslant 10$ fruit, percent attack and fecundity were inversely related in 1978 (Spearman's coefficient of rank correlation, $r_{s}=-.30$, $n=50, P<.05)$, but not in $1979\left(r_{s}=-.13, n=68\right.$, $P>.10)$ or $1980\left(r_{s}=-.04, n=58, P>.10\right)$. Limited data from 1977 also showed no significant decrease in percent attack with increasing fruit crop size $\left(r_{s}=-.29, n=27, P>.10\right)$. The lower average predation intensities in 1979 relative to the other years are also evident from Fig. 5.

Although higher individual fecundity did not consistently reduce the intensity of predation, more fecund plants nonetheless maintain an absolute advantage in escape from seed predation. Because there is no strong relationship, either positive or negative, between fecundity and percent attack, it follows that the absolute number of fruits attacked is a positive function of individual plant fecundity, i.e., more fecund plants attract more seed predators and incur more absolute damage (Table 1). However, the number of fruits escaping weevil attack is also a positive function of in- 


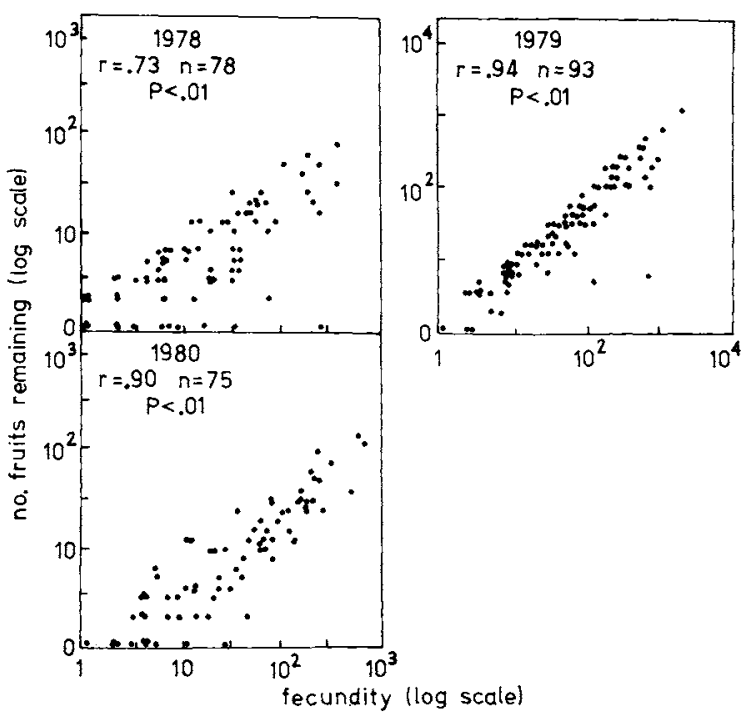

Fig. 6. Number of viable witch-hazel fruits remaining at the end of the growing season as a function of individual plant fecundity from 1978 to 1980 .

dividual fecundity (Table 1). All plants abort damaged fruits equally, with the result that, by the end of the growing season, the larger, more fecund plants mature a greater absolute number of viable fruits and seeds than do smaller, less fecund plants (Fig. 6). This occurs in all years, regardless of the average level of predation. As a consequence of the relatively low frequency of highly productive individuals in the population as a whole (Fig. 2), a few relatively fecund plants contribute disproportionately to annual seed production. Fifteen percent of the plant individuals produced $62 \%$ of all the viable fruits remaining at the end of the season in $1978,68 \%$ in 1979 , and $58 \%$ in 1980 .

Effect of spatial isolation.-The spatial distribution of witch-hazel is highly clumped, with plants occurring in relatively dense stands separated by $20 \mathrm{~m}$ or more from other stands. From the point of view of seed predation, the relevant distances are those between fruiting neighbors, since reproductives are both source and target for searching adult weevils. The mean neighbor distances of most reproductive individuals within stands are $2-3 \mathrm{~m}$, in contrast to the much greater distances between stands (Fig. 7). The generally

TABLE 1. Correlation $\dagger$ between individual witch-hazel fecundity and the absolute effects of fruit attack by weevils.

\begin{tabular}{lccc}
\hline \multicolumn{1}{c}{ Fecundity vs. } & 1978 & 1979 & 1980 \\
\hline Number of fruits attacked & $0.94^{* *}$ & $0.89^{* *}$ & $0.97^{* *}$ \\
Number of fruits not attacked & $0.63^{* *}$ & $0.96^{* *}$ & $0.61^{* *}$ \\
Number of plants & 82 & 93 & 86 \\
\hline
\end{tabular}

+ Pearson product-moment correlation $(r)$ on log-transformed data.

${ }^{* *} P<.01$.

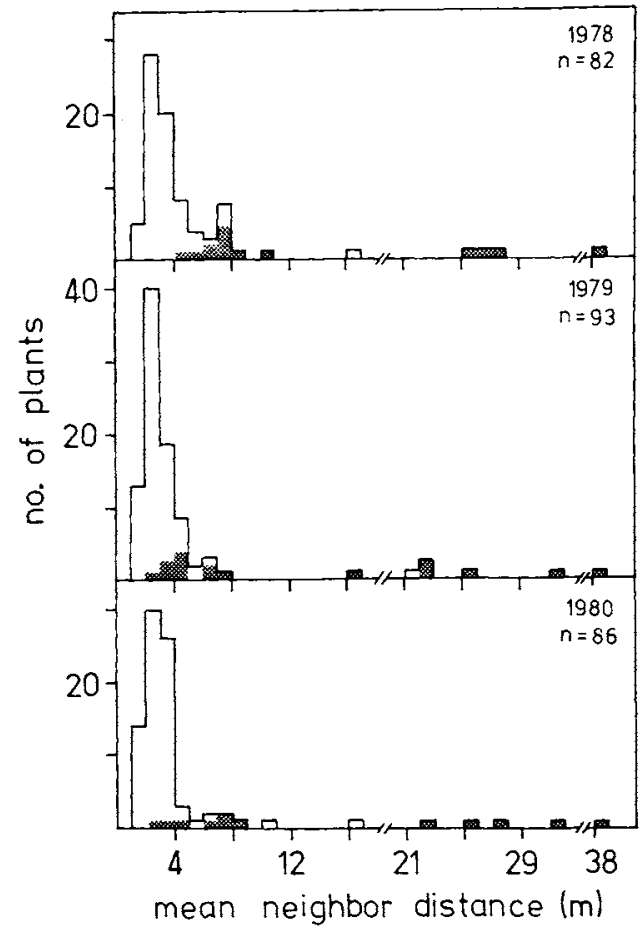

FIG. 7. Frequency distribution of mean neighbor distance (average of distances to three nearest fruiting conspecifics) for the witch-hazel plants in the 1978-1980 samples. Shaded area represents the plants specifically selected for their greater isolation from neighbors.

short interplant distances within stands are especially evident when individuals indicated by the shaded areas in Fig. 7 are not considered, since those plants were deliberately selected for their more extreme isolation from conspecifics. Such isolated individuals were difficult to locate in any quantity. The spatial distribution shifted toward shorter interplant distances in 1979 (Fig. 7) because more plants fruited in that year than in 1978 or 1980; thus, nonfruiting neighbors in 1978 often became fruiting neighbors in 1979.

The relative rarity of isolation could provide a disproportionately large advantage in escape from seed predation to those few individuals that do happen to establish far from conspecifics. In order to test this, plants were placed into one of three classes based on mean neighbor distance $(<5,5-10$, and $\geqslant 10 \mathrm{~m}$, respectively). The probability of being located by weevils (i.e., the percentage of plants with any fruit attack at all) declined significantly with distance category (test for linear trend in proportions [Snedecor and Cochran 1967]: for $1978, b=.22, s_{b}=.08$; for $1979, b=.16$, $s_{b}=.07$; for $1980, b=.13, s_{b}=.04$; all $P<.05$ ). However, as previously noted, small, low-fecundity plants may be found less often by weevils, and many of the isolated plants in the sample were also small. When the effect of relative spatial isolation was examined separately for plants with low fecundity $(<10$ 
TABLE 2. Probability of location of witch-hazel plants by weevils as a function of plant fecundity and plant spatial isolation.

\begin{tabular}{|c|c|c|c|c|}
\hline \multirow{2}{*}{$\begin{array}{l}\text { Mean } \\
\text { neighbor } \\
\text { distance } \\
(\mathrm{m})\end{array}$} & \multicolumn{4}{|c|}{$\%$ of plants with some fruits infested $(n)$} \\
\hline & 1978 & 1979 & 1980 & Combined \\
\hline & \multicolumn{4}{|c|}{ Fecundity: $<10$ fruits per plant* } \\
\hline$<5$ & $58(19)$ & $57(21)$ & $90(21)$ & $69(61)$ \\
\hline$\geqslant 5,<10$ & $40(10)$ & $0(2)$ & $67(3)$ & $40(15)$ \\
\hline \multirow[t]{2}{*}{$\geqslant 10$} & $0(3)$ & $0(2)$ & $50(4)$ & $22(9)$ \\
\hline & \multicolumn{4}{|c|}{ Fecundity: $\geqslant 10$ fruits per plant $\dagger$} \\
\hline$<5$ & $100(41)$ & $97(59)$ & $100(52)$ & $99(152)$ \\
\hline$\geqslant 5,<10$ & $83(6)$ & $100(4)$ & $100(3)$ & $92(13)$ \\
\hline$\geqslant 10$ & $100(3)$ & $80(5)$ & $100(3)$ & $91(11)$ \\
\hline
\end{tabular}

* Test for linear trend in proportions (Snedecor and Cochran 1967): 1978: $b=.25, s_{b}=.13, P=.055 ; 1979: b=.34$, $s_{b}=.17, P<.05 ; 1980: b=.20, s_{b}=.10, P<.05$.

$\dagger$ Test for linear trend not significant for 1978 and 1979; no test required for 1980

fruits) and plants with higher fecundity ( $\geqslant 10$ fruits), two results emerged (Table 2). First, the probability of location was significantly lower for low-fecundity plants as a group than for high-fecundity plants $\left(\chi^{2}{ }_{1978}=26.8, \chi^{2}{ }_{1979}=25.8, \chi^{2}{ }_{1980}=7.98 ; \mathrm{df}=1 ;\right.$ all $P<.05)$. Second, although the yearly samples are small, the lower probability of detection by weevils with increasing distance appears significant only for the small-plant category. Thus the overall distance effect was the result of an interaction of spatial isolation with plant size. Small, distant plants have a lower probability of attack by weevils, but isolation is not likely to prevent searching weevils from locating larger, more conspicuous plants.

If large interplant distances do not affect the probability of location of larger plants, they may nonetheless reduce the intensity of seed predation on individual fruit crops by reducing the number of successful encounters by weevils. Among the more fecund plants $(\geqslant 10$ fruits), percent fruit attack tended to decrease with increasing spatial isolation (Fig. 8; data are summarized according to distance category in the figure due to the small numbers of isolated plants). However, correlations between percent attack and mean neighbor distance were not significant in any year (Spearman's coefficient of rank correlation: $r_{s, 1978}=-.18$, $n=50 ; r_{s, 1979}=-.11, n=68 ; r_{s, 1980}=.09, n=58$; all $P>.10$ ). There was a large variance in predation intensity even among closely spaced plants. Sufficient distance data were not available for 1977. The declining trend seemed strongest in 1979, with four of the five very isolated plants having very little fruit infestation (Fig. 8).

\section{Weevil mortality}

Oviposition on a fruit does not necessarily result in the destruction of that fruit. An average of $26 \%$ of all eggs laid on witch-hazel fruits fail to hatch, and among

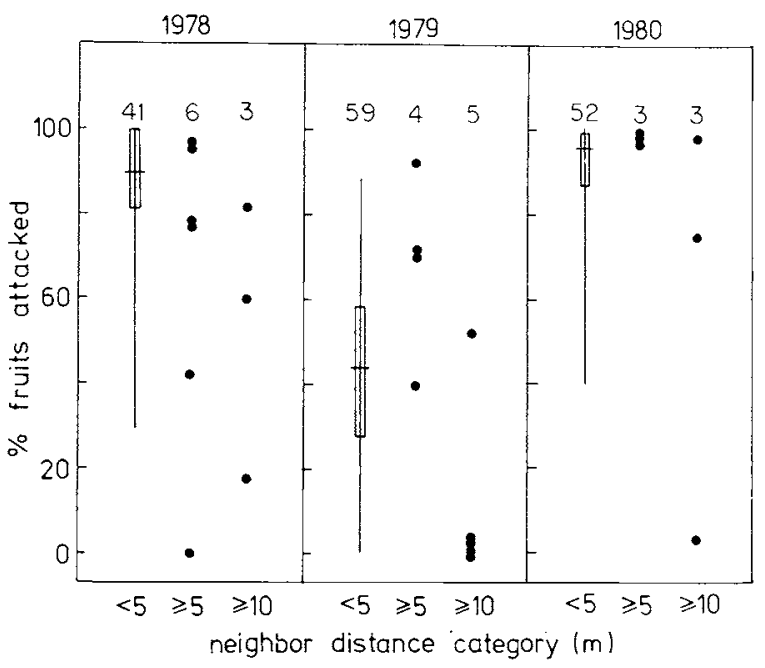

FIG. 8. Percent of individual witch-hazel fruit crops attacked by weevils as a function of mean neighbor distance category. Only plants with fecundities of $\geqslant 10$ fruits are included; numbers above each category are sample sizes. For the category $<5 \mathrm{~m}$, horizontal line is the median, the vertical line is the range, and the rectangle brackets the interval from the 25 th to 75 th percentile. Individual values are plotted separately for plants in the other two categories.

the larvae that do hatch successfully, another 53\% die in early instars, often before they damage the second seed in the fruit (De Steven 1981a). Any remaining undamaged seeds in such fruits continue to develop and mature. For the weevil, this egg and early larval mortality is relatively constant from year to year (De Steven 1981 $a$ ), but its effects on witch-hazel seed production are dependent upon the extent of fruit attack in any particular year. In 1978, when percent fruit attack was quite high, $63 \%$ of the viable fruits that remained had initially contained weevil eggs or larvae, while in 1979 , when predation intensity was much reduced, only $29 \%$ of the remaining viable fruits had initially been attacked by the weevils ( $n=219$ and 907 , respectively). Comparable data for 1980 were not obtained, but would probably have exceeded the $63 \%$ of 1978 , since predation intensities in that year were nearly $100 \%$. Thus weevil mortality within fruits tends to counter the effects of high predation intensities in poor fruiting years.

\section{Discussion}

The fluctuating pattern of fruit production is a key feature in understanding the demographic impact of Pseudanthonomus seed predation on witch-hazel. The weevil is host specific and univoltine; thus, its population dynamics are directly linked to these fluctuations (De Steven 1982). In poor fruiting years, oviposition sites are limited due to the low fruit abundances, attack percentages on fruit crops are high, and the size of the weevil generations produced is small. Attack need not equal $100 \%$ in order for the weevils to be 
resource-limited in such years, since searching weevils may be unable to find particular individual plants because these are small, have very few fruits, or are extremely isolated from conspecifics. Following poor fruiting years, the fruit crop in a productive year "satiates" the relatively small weevil population, with the result that seed predation intensities are substantially lower, and many more seeds escape predation. Continued high fruit production would allow annual increases in weevil numbers and in fruit attack; however, any reductions in fruit production following a good year will lower weevil population size again, and fruit attack will be quite high. The result for witchhazel is a pulse of successful seed production in the occasional productive year that satiates the seed predator population. Similar patterns of high seed predation in years of poor seed production have been observed in a number of forest trees, where fluctuating fruiting patterns also appear to regulate seed predator populations (Christisen 1955, Abrahamson and Kraft 1965, Mattson 1971, Miller 1973, Gardner 1977).

Silvertown (1980) emphasizes that general mechanisms exist for generating a periodic, or mast, fruiting pattern. Coarse supra-annual fruiting synchrony can be enforced by environmental cues favoring good fruit crops (e.g., Wenger 1957). There also appears to be a negative feedback of a large fruit crop upon internal resource allocation for subsequent crops, such that good fruiting years seldom occur sequentially (Matthews 1963, Kozlowski 1971). Against this background, Silvertown (1980) found empirical support for the hypothesis (Janzen 1971) that seed predators can act as a selective force favoring mast fruiting, due to the excessive seed losses incurred by the asynchronous individuals that fruit in off-peak years. Mattson (1978) suggested that high predispersal seed predation in poor fruiting years might also enhance fruiting periodicity if, by preventing seeds from maturing, the resources that would have been used for maturation are instead stored for use in a subsequent, and hence larger, crop. This mechanism is especially interesting, because it suggests an effect of seed predation, exerted directly on the parent plant, that might increase fruiting periodicity over a shorter time scale than that required for selection against asynchronously fruiting individuals through reduction in their progeny contribution to later generations. While the masting habit appears to be underrepresented among shrubs in comparison with trees (Silvertown 1980), witch-hazel has highly edible seeds susceptible to extremely heavy predation, and given its seed predator's host specificity, any tendencies to increase fruiting periodicity would appear to be selectively favored.

A further consideration is the 2-yr dormancy of witch-hazel seeds prior to germination (Sandahl 1941). Shoemaker (1905) reported high seedling recruitment $2 \mathrm{yr}$ following a good witch-hazel fruit crop and almost no seedling production $2 \mathrm{yr}$ after a crop failure. But while the pulse of high seed production in good fruiting years may carry over into a pulse of high seedling recruitment, the extended seed dormancy period may place those seedlings into a year when conditions for seedling establishment are poor, and seeds produced in poor fruiting years may contribute disproportionately to witch-hazel recruitment if they germinate in years especially favorable for seedling establishment.

Within plant populations, Moore (1978a) has suggested that individual variation in susceptibility to seed predation may indicate potential selective pressures on those plant traits that influence this variation. Such interpretations require caution, because the variation in plant traits that contribute to relative escape from seed predation may be primarily phenotypic rather than genotypic in origin. Nonetheless, differential seed predation may influence the relative contributions of individuals to short-term population dynamics. I considered two factors likely to influence relative predation intensity on witch-hazel individuals: plant fecundity and plant spatial isolation.

Variation in individual fecundity did not result in differential seed predation intensity among witch-hazel plants in any given year, thus the relative seed outputs of different-sized plants were not altered beyond the variation in fecundity already existing. That this and other studies (Moore 1978b, De Steven 1981b) have failed to find such a relative advantage of plant fecundity (or plant size, a correlate of fecundity) suggests that large seed crops are generally more conspicuous and attract more seed predators than small crops. Seed predation is therefore not acting selectively to favor some individuals over others in any particular year. The demographic significance of the greater absolute seed output of larger plants is a timedependent consequence of witch-hazel's perennial habit. Individuals will contribute most to their own reproduction and to demographic processes when they are older, since plant size and fecundity are increasing functions of age. Also, while individuals with inherently high fecundity will be favored reproductively, so also will those plants that happen to establish in favorable sites promoting rapid, vigorous growth that results in phenotypically higher productivity.

Spatial isolation from conspecifics is often cited as a factor likely to reduce predation on individual seed crops, and some models use this concept to account for high tree species diversity in tropical forests as the result of a lowered probability of seed destruction with increased distance from parent trees (Connell 1970, Janzen 1970). Hubbell (1980) has demonstrated that plants generally lack the uniform spatial distributions predicted by these models and that spacing due to density-dependent seed predation cannot alone permit large numbers of plant species to coexist. However, his analysis only indirectly addresses the question of whether, in particular cases, seed predators act in a distance-dependent manner to result in lower seed 
predation on individuals isolated from conspecifics. While some studies have indeed demonstrated an inverse relationship between seed predation intensity and plant spatial isolation (Vandermeer 1974, Silander 1978), many others have failed to find such a relationship (Connell 1970, Wilson and Janzen 1972, Platt et al. 1974, Moore 1978b, De Steven 1981b).

Witch-hazel exhibits a clumped spatial distribution; seed dispersal distances are probably not more than a few metres (Billington 1943). Within populations, spatial isolation of individuals outside of these clumps reduced the susceptibility of small, low-fecundity plants to seed predation, but larger individuals were likely to be found regardless of distance from neighbors. Distance may also reduce the extent of fruit attack on larger plants, although the effect was weak. These results suggest an initial reproductive advantage to small, young witch-hazel plants that establish far from conspecifics in comparison with similar-sized plants in existing stands. However, this advantage is likely to decrease as these plants grow larger and produce larger, more conspicuous seed crops. Consequently, there would probably be no long-term change in the degree of spatial aggregation of witch-hazel populations and no long-term advantage to increasing interplant distance.

Other plant traits could influence differential seed predation on individuals, but they were not examined in this study. Since witch-hazel fruit initiation is synchronous because of the climatic timing of fruit-set in spring, within-year variation in individual fruiting phenology (e.g., Augspurger 1981) is unlikely to account for any differential seed predation. Plant chemistry could also influence predation intensity if some individuals had higher concentrations of potentially deterrent compounds in fruits than others (e.g., Moore 1978b). However, in witch-hazel such a chemical factor might more likely operate at the level of affecting weevil larval mortality within fruits rather than influencing the probability of attack on different plants, since all plants appear suitable for weevil oviposition. Possibly at least a portion of the weevil larval mortality within witch-hazel fruits is the result of a chemical antibiosis effect.

In summary, the seed weevil Pseudanthonomus hamamelidis affects witch-hazel recruitment most strongly at the population level by generating an episodic pattern of high seed production in good seed years that satiate seed predators alternated with low production in poor years when seed predation is extensive. This pattern is an outcome of the synchronized fruiting behavior of individual plants and thus favors individuals whose fruit crops vary in concert with conspecifics. However, beyond this general effect, seed predation does not appear to distinguish among individuals, at least with respect to their fecundity or spatial isolation, except where small, inconspicuous plants gain a temporary advantage in re- duced seed loss when they are spatially isolated from neighbors.

\section{ACKNOWLEDGMENTS}

This paper originates from a dissertation submitted in partial fulfillment of the requirements for the Ph.D. in Biological Sciences at the University of Michigan. I thank the Museum of Zoology, University of Michigan, for permission to work on the George Reserve. Funds were provided by Sigma Xi, the University of Michigan, and a George Reserve Scholarship. S. Denzer, Z. Freivalds, and M. Turner aided me in the field in 1977. My dissertation committee, F. Evans, D. Rabinowitz, B. Rathcke, J. Vandermeer, and J. Witter, provided help and encouragement throughout the course of the study. C. Bach and C. Augspurger made useful suggestions for improving the manuscript. Special thanks go to D. Bay for exceptional photographic services.

\section{Literature Cited}

Abrahamson, L. P., and K. J. Kraft. 1965. A population study of the cone moth Laspeyresia toreuta Grote in Pinus banksiana stands. Ecology 46:561-563.

Augspurger, C. K. 1981. Reproductive synchrony of tropical plants: experimental studies on effects of pollinators and seed predators on Hybanthus prunifolius (Violaceae). Ecology 62:775-788.

Billington, C. 1943. Shrubs of Michigan. Bulletin 20, Cranbrook Institute of Science, Bloomfield Hills, Michigan, USA.

Blatchley, W. S., and C. W. Leng. 1916. Rhynchophora or weevils of North Eastern America. Nature Publishing, Indianapolis, Indiana, USA.

Bradford, D. F., and C. C. Smith. 1977. Seed predation and seed number in Scheelea palm fruits. Ecology 58:667673.

Brown, J. H., O. J. Reichman, and D. W. Davidson. 1979. Granivory in desert ecosystems. Annual Review of Ecology and Systematics 10:201-227.

Burke, H. R. 1972. Observations on the life history of Pseudanthonomus krameriae, with descriptions of larva and pupa (Coleoptera: Curculionidae). Annals of the Entomological Society of America 65:619-622.

Cantrall, I. J. 1943. The ecology of the Orthoptera and Dermaptera of the George Reserve, Michigan. Miscellaneous Publications of the Museum of Zoology, University of Michigan 54:1-182.

Christisen, D. M. 1955. Yield of seed by oak in the Missouri Ozarks. Journal of Forestry 53:439-441.

Connell, J. H. 1970. On the role of natural enemies in preventing competitive exclusion in some marine animals and in rain forest trees. Pages 298-310 in P. J. den Boer and G. R. Gradwell, editors. Dynamics of populations. Proceedings of the Advanced Study Institute on Dynamics of numbers in populations (Oosterbeek). Centre for Agricultural Publishing and Documentation, Wageningen, The Netherlands.

De Steven, D. 1981a. Abundance and survival of a seedinfesting weevil, Pseudanthonomus hamamelidis (Coleoptera: Curculionidae), on its variable-fruiting host plant, witch-hazel (Hamamelis virginiana). Ecological Entomology 6:387-396.

1981b. Predispersal seed predation in a tropical shrub (Mabea occidentalis, Euphorbiaceae). Biotropica 13: $146-150$.

- 1982. Seed production and seed mortality in a temperate forest shrub (witch-hazel, Hamamelis virginiana). Journal of Ecology 70:437-443.

Dolinger, P. M., P. R. Ehrlich, W. L. Fitch, and D. E. Breedlove. 1973. Alkaloid and predation patterns in Colorado lupine populations. Oecologia (Berlin) 13:191-204. 
Flint, F. F. 1957. Megasporogenesis and megagametogenesis in Hamamelis virginiana L. Virginia Journal of Science 8: 185-189.

Gardner, G. 1977. The reproductive capacity of Fraxinus excelsior on the Derbyshire limestone. Journal of Ecology 65: $107-118$.

Graenicher, S. 1906. Some notes on the pollination of flowers. Bulletin of the Wisconsin Natural History Society 4: $12-21$.

Harper, J. L. 1977. Population biology of plants. Academic Press, London, England.

Harper, J. L., P. H. Lovell, and K. G. Moore. 1970. The shapes and sizes of seeds. Annual Review of Ecology and Systematics 1:327-356.

Hubbell, S. P. 1980. Seed predation and the coexistence of tree species in tropical forests. Oikos 35:214-229.

Janzen, D. H. 1969. Seed-eaters vs. seed size, number, toxicity, and dispersal. Evolution 23:1-27.

- 1970. Herbivores and the number of tree species in tropical forests. American Naturalist 104:501-528.

1971. Seed predation by animals. Annual Review of Ecology and Systematics 2:465-492.

Kozlowski, T. T. 1971. Growth and development of trees. Volume II. Cambial growth, root growth, and reproductive growth. Academic Press, New York, New York, USA.

Matthews, J. D. 1963. Factors affecting the production of seed by forest trees. Forestry Abstracts 24:i-xiii.

Mattson, W. J. 1971. Relationship between cone crop size and cone damage by insects in red pine seed-production areas. Canadian Entomologist 103:617-621.

- 1978. The role of insects in the dynamics of cone production of red pine. Oecologia (Berlin) 33:327-349.

Miller, W. E. 1973. Insects as related to wood and nut production. In Black walnut as a crop. United States Forest Service General Technical Report NC-4, North Central Forest Experiment Station, St. Paul, Minnesota, USA.

Moore, L. R. 1978a. Seed predation in the legume Crotalaria. I. Intensity and variability of seed predation in native and introduced populations of $C$. pallida Ait. Oecologia (Berlin) 34: 185-202.

- 1978b. Seed predation in the legume Crotalaria. II. Correlates of interplant variability in predation intensity. Oecologia (Berlin) 34:203-223.

Platt, W. J., G. R. Hill, and S. Clark. 1974. Seed production in a prairie legume (Astragalus canadensis L.). Interactions between pollination, predispersal seed predation, and plant density. Oecologia (Berlin) 17:55-63.

Preston, R. J. 1948. North American trees. Iowa State University Press, Ames, Iowa, USA.

Sandahl, P. L. 1941. Seed germination. Parks and Recreation 24:508.

Shoemaker, D. N. 1905. On the development of Hamamelis virginiana. Botanical Gazette 39:248-266.

Silander, J. A. 1978. Density-dependent control of reproductive success in Cassia biflora. Biotropica 10:292-296.

Silvertown, J. W. 1980. The evolutionary ecology of mast seeding in trees. Biological Journal of the Linnean Society 14:235-250.

Smith, C. C. 1970. The coevolution of pine squirrels (Tamiasciurus) and conifers. Ecological Monographs 40:349-371.

Snedecor, G. W., and W. G. Cochran. 1967. Statistical methods. Iowa State University Press, Ames, Iowa, USA.

United States Forest Service. 1974. Seeds of woody plants in the United States. Agricultural Handbook 450, United States Forest Service, Washington, D.C., USA.
Vandermeer, J. H. 1974. Relative isolation and seed predation in Calliandra grandiflora, a mimosaceous legume from the highlands of Guatemala. Biotropica 6:267-268.

Wenger, K. F. 1957. Annual variation in the seed crops of loblolly pine. Journal of Forestry 55:567-569.

Wilson, D. E., and D. H. Janzen. 1972. Predation on Scheelea palm seeds by bruchid beetles: seed density and distance from the parent palm. Ecology 53:954-959.

Wood, G. W. 1974. Witch-hazel. Pages 154-157 in J. D. Gill and W. M. Healy, editors. Shrubs and vines for northeastern wildlife. General Technical Report NE-9, United States Forest Service, Northeast Forest Experiment Station, Upper Darby, Pennsylvania, USA.

Zimmerman, M. 1980. Reproduction in Polemonium: predispersal seed predation. Ecology 61:502-506.

\section{APPENDIX 1}

Annual variation in median (25-75th percentile) fecundity of witch-hazel, by site.

\begin{tabular}{lrllllll}
\hline \hline & \multicolumn{2}{c}{1978} & \multicolumn{2}{c}{1979} & & \multicolumn{2}{c}{1980} \\
\cline { 2 - 3 } \cline { 7 - 7 } Site & Fecundity & $n$ & Fecundity & $n$ & & Fecundity & $n$ \\
\hline L1 & $15(4-31)$ & 25 & $34(8-244)$ & 27 & $39(7-85)$ & 21 \\
L2 & $30(6-48)$ & 25 & $47(11-164)$ & 26 & $18(4-83)$ & 24 \\
S1 & $7(4-61)$ & 19 & $77(9-210)$ & 22 & $25(7-172)$ & 20 \\
S2 & $36(6-76)$ & 13 & $30(7-89)$ & 19 & $34(9-69)$ & 21 \\
\hline
\end{tabular}

\section{APPENDIX 2}

Percent of individual witch-hazel fruit crops attacked by weevils from 1978 to 1980 , by site. Data are given as median percent $(25-75$ th percentile) for plants with fecundities $\geqslant 10$ fruit.

\begin{tabular}{cccccccc}
\hline \hline & \multicolumn{2}{c}{1978} & & \multicolumn{2}{c}{1979} & \multicolumn{2}{c}{1980} \\
\cline { 2 - 4 } \cline { 5 - 7 } Site & $\begin{array}{c}\% \text { fruit } \\
\text { attacked }\end{array}$ & $n$ & $\begin{array}{c}\text { \% fruit } \\
\text { attacked }\end{array}$ & $n$ & $\begin{array}{c}\% \text { fruit } \\
\text { attacked }\end{array}$ & $n$ \\
\hline L1 & $100(96-100)$ & 15 & $47(38-67)$ & 19 & $99(97-100)$ & 14 \\
L2 & $86(77-92)$ & 18 & $43(30-50)$ & 20 & $90(83-96)$ & 16 \\
S1 & $82(53-89)$ & 9 & $22(15-34)$ & 15 & $96(88-98)$ & 13 \\
S2 & $60(42-82)$ & 8 & $52(13-71)$ & 14 & $94(81-97)$ & 15 \\
\hline
\end{tabular}

\section{APPENDIX 3}

Annual variation in median (25-75th percentile) viable witchhazel fruits remaining at the end of the growing season, by site.

\begin{tabular}{lllllllll}
\hline & \multicolumn{2}{c}{1978} & & \multicolumn{2}{c}{1979} & & \multicolumn{2}{c}{1980} \\
\cline { 2 - 3 } Site & No. fruits & $n$ & & No. fruits & $n$ & & No. fruits & $n$ \\
\hline L1 & $2(0-4)$ & 24 & & $23(6-184)$ & 27 & & $3(1-25)$ & 20 \\
L2 & $8(2-17)$ & 25 & & $13(8-38)$ & 26 & & $5(2-24)$ & 22 \\
S1 & $4(2-12)$ & 16 & & $41(8-117)$ & 21 & & $11(3-33)$ & 14 \\
S2 & $4(1-13)$ & 13 & & $12(2-32)$ & 19 & & $10(2-20)$ & 19 \\
\hline
\end{tabular}

